\title{
Magnetic minerals as recorders of weathering, diagenesis, and paleoclimate: a core-outcrop comparison of Paleocene-Eocene paleosols in the Bighorn Basin, WY, U.S.A.
}

\author{
Daniel P. Maxbauer ${ }^{\mathrm{a}, \mathrm{b}, *}$, Joshua M. Feinberg ${ }^{\mathrm{a}, \mathrm{b}}$, David L. Fox ${ }^{\mathrm{b}}$, William C. \\ Clyde $^{\mathrm{c}}$ \\ ${ }^{a}$ Institute for Rock Magnetism, University of Minnesota, Minneapolis, MN \\ ${ }^{b}$ Department of Earth Sciences, University of Minnesota, Minneapolis, MN \\ ${ }^{c}$ Department of Earth Sciences, University of New Hampshire, Durham, NH, U.S.A.
}

\begin{abstract}
Magnetic minerals in paleosols hold important clues to the environmental conditions in which the original soil formed. However, efforts to quantify parameters such as mean annual precipitation (MAP) using magnetic properties are still in their infancy. Here, we test the idea that diagenetic processes and surficial weathering affect the magnetic minerals preserved in paleosols, particularly in pre-Quaternary systems that have received far less attention compared to more recent soils and paleosols. We evaluate the magnetic properties of non-loessic paleosols across the Paleocene-Eocene Thermal Maximum (a short-term global warming episode that occurred at 55.5 Ma) in the Bighorn Basin, WY. We compare data from nine paleosol layers sampled from outcrop, each of which has been exposed to surficial weathering, to the equivalent paleosols sampled from drill core, all of which are preserved below a pervasive surficial weathering front and are presumed to be unweathered. Comparisons reveal an increase in magnetization in outcrops compared with core equivalents, which is principally driven by secondary hematite production. Authigenic hematite production in outcrops presents a complication for goethite-hematite based paleoprecipitation proxies where estimates will be biased toward drier climate regimes. The occurrence of low coercivity minerals is more consistent between core and outcrop. However, we propose an
\end{abstract}

*Corresponding author. E-mail address: maxba001@umn.edu

Preprint submitted to Earth and Planetary Science Letters

July 15, 2016

(C) 2016. This manuscript version is made available under the Elsevier user license http://www.elsevier.com/open-access/userlicense/1.0/ 
alteration process for pedogenic magnetite that is observed in both core and outcrop, where pedogenic magnetite becomes progressively oxidized leading to higher mean coercivities and broader coercivity distributions compared to modern pedogenic magnetite. This combination of diagenetic processes and surface weathering influences the magnetic properties of paleosols. Despite these changes, magnetic enhancement ratios from B-horizons correlate with independent MAP estimates from geochemical proxies, which suggests that paleoprecipitation information is preserved. Future work should continue to address these complications by developing useful protocols that isolate the magnetic properties that are most resistant to alteration and remain strong indicators of MAP and climate.

Keywords: weathering, diagenesis, environmental magnetism, paleosol, paleoprecipitation

\section{Introduction}

The magnetic properties of soils and paleosols are often used to make

$4 \quad$ (see reviews by Maher, 1998; Maxbauer et al., 2016). This is possible largely

5 because magnetic minerals such as goethite $(\mathrm{FeOOH})$, hematite $\left(\alpha-\mathrm{Fe}_{2} \mathrm{O}_{3}\right)$,

6 magnetite $\left(\mathrm{Fe}_{3} \mathrm{O}_{4}\right)$, and maghemite $\left(\gamma-\mathrm{Fe}_{2} \mathrm{O}_{3}\right)$ form through a combination

7 of processes that are often critically dependent on soil moisture Maxbauer et al. 2016, and references therein). Many studies have established empiri-

9 cal, quantitative relationships between pedogenic iron oxide minerals and the

10 mean annual precipitation (MAP) under which the soil formed (e.g., Maher

11 and Thompson, 1995, Geiss et al., 2008; Long et al., 2011; Hyland et al.,

12 2015). These quantitative methods, along with earlier more qualitative in-

terpretations, hold enormous potential for understanding environmental vari- 
ability in the deep past. Two recent studies have highlighted the potential for methods based on the ratio of goethite-to-hematite $(G / H$; Hyland et al., 2015) and direct estimates of pedogenically produced magnetite (Geiss et al., 2008). The $G / H$ method presented by Hyland et al. (2015) was calibrated using modern soils that formed over a wide range of MAP values (200 - 3000 $\left.\mathrm{mm} \mathrm{yr}^{-1}\right)$. In contrast, the calibrations of Geiss et al. (2008) are similar to other pedogenic magnetic susceptibility based proxies (e.g., Maher and

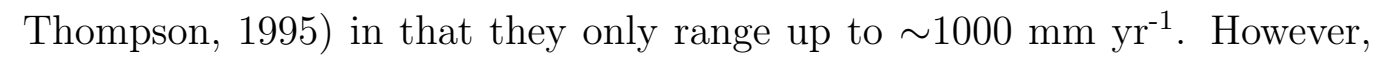
Geiss et al. (2008) offered calibrations between MAP and magnetic enhancement ratios $\left(M_{B} / M_{C}\right.$, where $M$ is the mean value of a generic magnetic property for the $\mathrm{B}$ and $\mathrm{C}$ soil horizons) or direct measures of pedogenic magnetite (e.g., ratio of anhysteretic to isothermal remanence) that may prove useful in expanding methods developed on loessic soils into other soil types and climatic regimes.

Most paleosol studies are based on observations from Quaternary or younger loess-paleosol sequences (e.g., Geiss et al., 2008; Maher and Thompson, 1995; Maher et al., 2003) so little is known about the magnetic properties of more ancient paleosols as paleoclimatic indicators. The few studies that examine this topic report low magnetic susceptibility $(\chi)$ in ancient paleosols compared to modern soils (Rankey and Farr, 1997; Cogoini et al., 2001; Retallack et al., 2003, Tramp et al., 2004). However, in some ancient systems 

47 2015).

48

there is evidence for preservation of pedogenic magnetic mineral assemblages that may be useful for reconstructing past environmental conditions (Rankey and Farr, 1997; Cogoini et al., 2001; Tramp et al., 2004; Morón et al., 2013; Hyland et al., 2015). Despite these exciting suggestions, there remains a general lack of information regarding the role of diagenesis and weathering in altering the original magnetic mineral assemblages in ancient paleosols, which limits our ability to interpret environmental conditions from ancient paleosol sequences with confidence. We must learn more about the diagenetic changes that affect soil magnetic mineral assemblages throughout their transformation into paleosols, throughout the subsequent burial history and exposure to chemically variable groundwater, and throughout their weathering history (for a recent review on magnetic mineral diagenesis, see Roberts,

Here, we examine these processes in paleosols preserved at the Polecat Bench locality in the Bighorn Basin, Wyoming (Figure 11). The Bighorn Basin Coring Project (BBCP; Clyde et al., 2013) recovered nearly 900 meters of sediment core from three localities in the Bighorn Basin, including Polecat Bench. Core scan images (Figure 2A) clearly indicate that oxidative weathering has altered sediment color to depths of up to 25 meters below the ground surface (Clyde et al., 2013). This observation calls into question whether magnetic mineral assemblages in paleosol outcrops reflect the 
original pedogenic assemblage and the environmental conditions in which they formed. This question has important implications for applying most magnetic-based paleoprecipitation proxies to ancient systems since they assume that the magnetic minerals preserved in paleosols are pedogenic and are not significantly altered by subsequent diagenesis and late-stage weathering.

The presence of the same paleosols in both BBCP cores and nearby outcrops presents an opportunity to test whether surficial weathering of outcrops significantly affects magnetic mineral preservation. We present magnetic data from nine marker bed paleosols, which were sampled from both core and outcrop (Figure 3). All paleosols occur well below the oxidative weathering front in the sediment core and we assume that these sediments are largely unweathered compared to equivalent outcrop exposures (see Figure 2). Both core and outcrop paleosols have likely been subjected to various long-term diagenetic processes (for example, interaction with fluids and elevated temperatures post-burial and before exposure of the basin). We compare magnetic properties of the Bighorn Basin paleosols to those of some modern soils to evaluate the effects that diagenesis can have on magnetic mineral preservation, independent from weathering.

Our record spans the Paleocene-Eocene Thermal Maximum (PETM, 55.5 Ma), which was a rapid global warming event driven by a massive release of isotopically light carbon into the mixed atmosphere/ocean system (see re- 

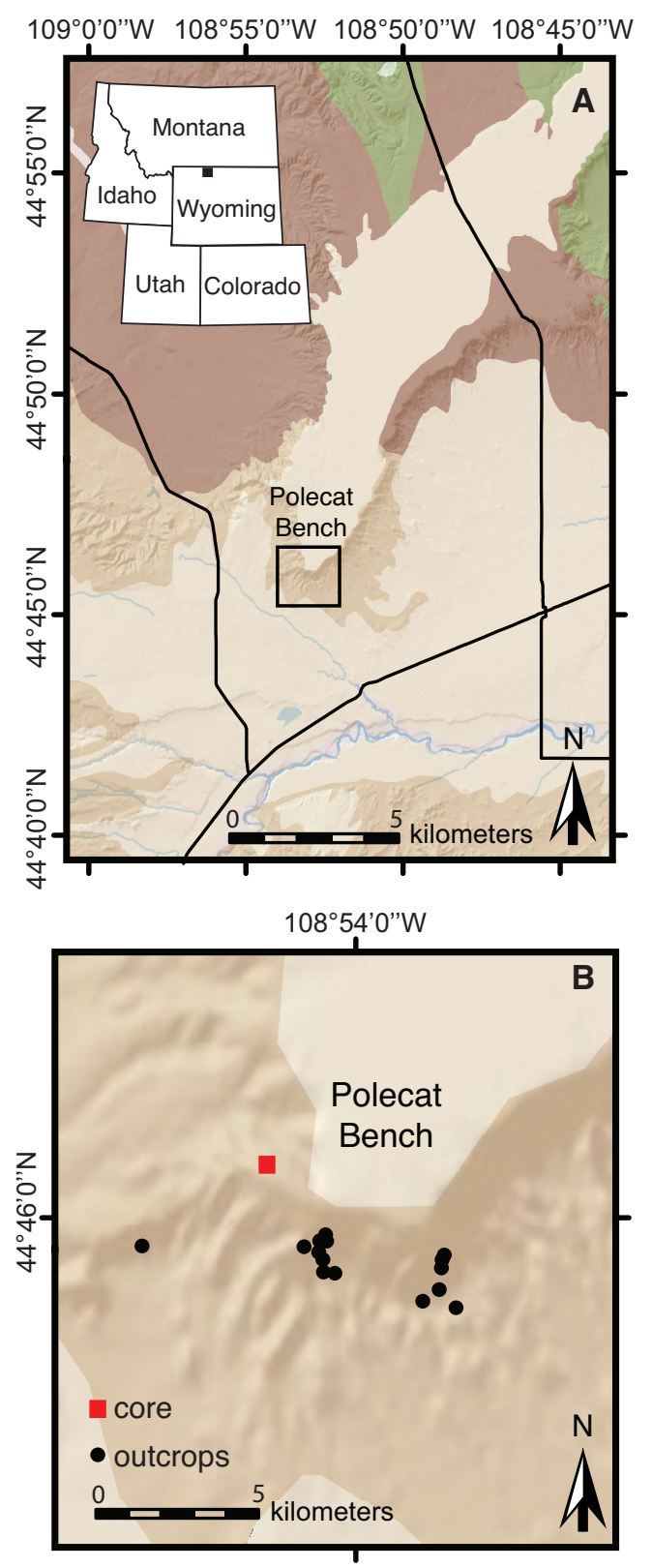

Figure 1: Maps of the study site at Polecat Bench in the Bighorn Basin, WY. A. Map of the northern Bighorn Basin. The highlighted and labeled box indicates the study area at Polecat Bench. The location of the study site in Wyoming is indicated in the inset of panel A. B. Polecat Bench locality with sampling locations indicated for outcrop paleosols (black circles) and coring location (red square). Color guide: darkest brown = Paleocene Fort Union Formation, dark tan $=$ Paleocene-Eocene Willwood Formation, light tan $=$ Quaternary gravels, and green $=$ Cretaceous units. 
view by McInerney and Wing, 2011). In the Bighorn Basin, the PETM was associated with a transient precipitation decrease that has been well documented in qualitative and quantitative paleoflora records (Wing et al., 2005) and from paleosol geochemistry and morphology (Kraus and Riggins, 2007; Adams et al., 2011; Kraus et al., 2015). We compare our rock magnetic record to a recent study of MAP estimates derived from geochemical weathering indices (Kraus et al. 2015) to evaluate whether magnetic mineral assemblages in these paleosols record paleoprecipitation changes during the PETM.

\section{Geological Setting}

The Bighorn Basin in northwestern Wyoming is a NW-to-SE trending intermontane basin that formed in response to local subsidence and regional uplift during the Laramide orogeny throughout late Cretaceous to Paleogene time (Figure 1: Gingerich, 2001). Paleocene and Eocene sediments of the Willwood Formation are well exposed at the Polecat Bench locality in the northern reaches of the basin (Gingerich, 2001; Kraus, 2001). These sediments have been the focus of extensive research due to interest in biotic and climatic changes associated with the PETM Clyde et al., 2013; Bowen et al., 2015).

Paleosols within the Willwood Formation, including the marker bed paleosols studied here, have all been described extensively by previous workers 

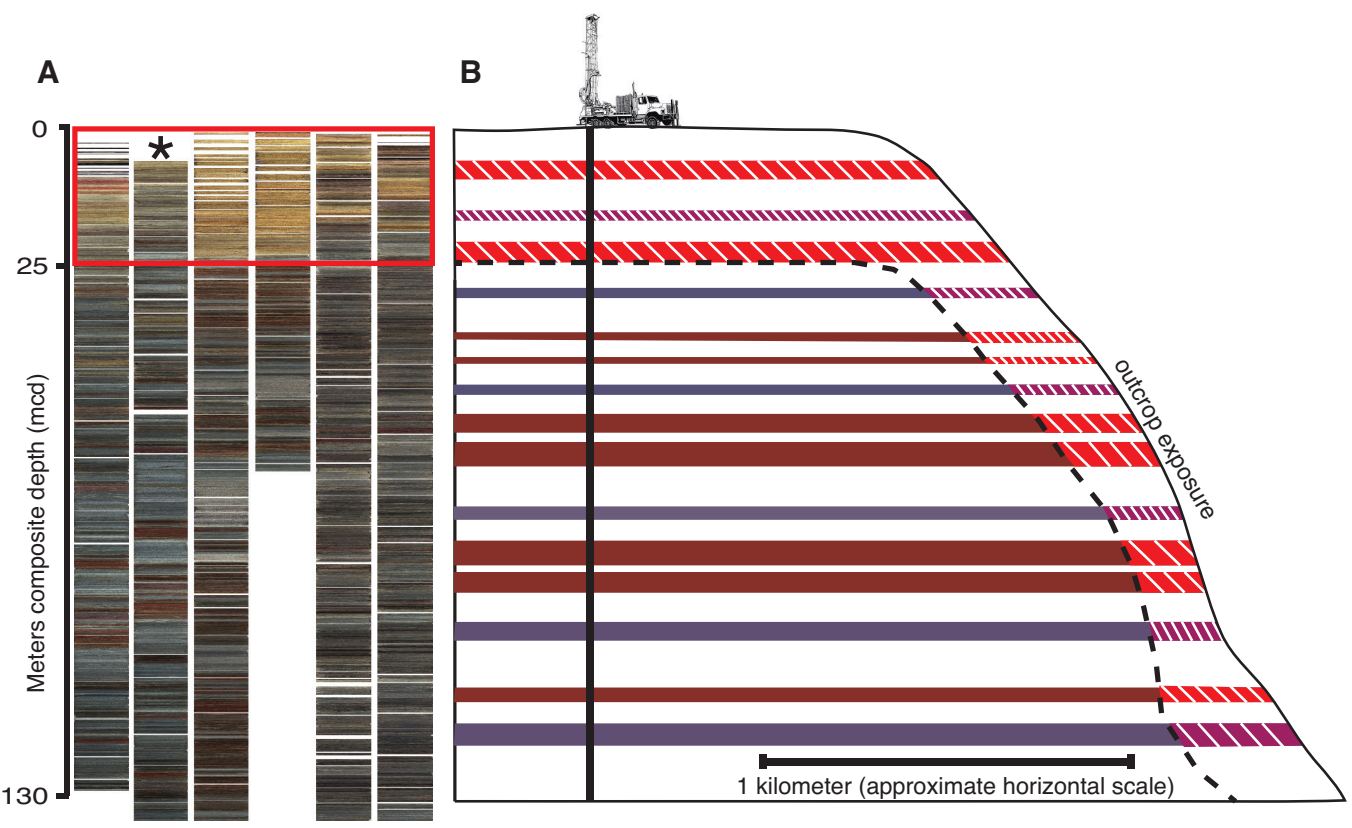

Figure 2: A. Line scan images from sediment cores recovered by the Bighorn Basin Coring Project (BBCP; Clyde et al., 2013). The approximate thickness of the weathering zone in sediment cores, as determined by color changes, is highlighted by the red box around the upper 25 meters of core. The asterisk in the red box highlights the Polecat Bench sediment core that is the focus of this study. B. Schematic illustration of how the weathering front (indicated with brighter, hashed colors) has affected outcrop exposures. Colored horizons indicate laterally continuous paleosols that are preserved in both core and outcrop. The drilling rig and black vertical line approximates a core location. Paleosols in the sediment core below the weathered zone are presumably relatively unweathered compared to their laterally equivalent exposure in outcrop.

(Kraus, 2001; Kraus and Hasiotis, 2006; Kraus and Riggins, 2007; Smith et al., 2008; Kraus et al., 2013, 2015). At Polecat Bench, paleosols are sorted into two general categories based on their B-horizon color. Red paleosols are characterized by a main red mudstone to silty mudstone B-horizon that is sometimes overlain by a grey or yellow-brown A horizon. Calcium carbonate nodules, slickensides, and grey mottles with red or purple rims are common in red paleosols and have been interpreted to represent generally well-drained 
and oxidizing conditions (Kraus and Hasiotis, 2006). In contrast, the purple paleosols are characterized by a purple mudstone B-horizon with abundant yellow-brown mottling and nodules, a lack of calcium carbonate nodules, abundant grey mottles with red rims, and slickensides (Kraus and Hasiotis, 2006).

Red paleosols are associated with generally dry climatic conditions where seasonal wetting and drying drove nucleation and growth of calcium carbonate nodules as well as the shrink-swell slickenside structures Kraus and Hasiotis, 2006). Purple paleosols are interpreted to represent more poorly drained conditions likely reflecting increased moisture and precipitation Kraus and Hasiotis, 2006; Kraus and Riggins, 2007). These qualitative interpretations of paleosol color and climatic conditions are reinforced by a semi-quantitative morphology index (Adams et al. 2011) and quantitative geochemical weathering indices (Kraus and Riggins, 2007; Kraus et al., 2013, 2015) that produce similar reconstructions for paleoprecipitation within the Bighorn Basin.

\section{Methods}

\subsection{Sampling}

All outcrop marker bed profiles were identified within the stratigraphic framework of Gingerich (2001) (also used by Abdul Aziz et al., 2008). Previous work has established correlations between the Gingerich (2001) outcrop 
section and the sediment cores recovered by the BBCP (see Bowen et al. 2015). We utilized these correlations and confirmed all relationships using line scan images prior to sampling of core sediments (see Figure 3). Depth below the surface for the Polecat Bench core studied here (core 2B) was converted to meters composite depth (mcd) following Bowen et al. (2015) using standards determined by the BBCP science team. All outcrop profiles were projected onto the mcd scale using either the top or base of paleosol B-horizons to anchor correlations.

In an effort to collect the freshest outcrop samples possible, and thus to mimic the sampling routine normally used in outcrop settings, the uppermost 0.5 to $1 \mathrm{~m}$ of rock was removed before paleosol samples were collected in the field. For each marker bed, samples were taken at $5 \mathrm{~cm}$ intervals through B-horizons and at $10 \mathrm{~cm}$ intervals through $\mathrm{C}$ (parent material) and A-horizons (when present). In order to assess the reproducibility of magnetic properties in individual paleosols, we collected additional profiles (with the number of profiles collected in parentheses) for four marker beds at lateral distances ranging from $\sim 10$ 's of meters to nearly a kilometer from the original profile (see Figure 1): Purple-Red Mudstone (3), Red Mudstone (2), Purple-2 (3), and Top Red A (3). All designations for the studied paleosols and their stratigraphic order are indicated in Figure 3. This approach allows us to quantify magnetic variability in soils that were originally developed in 


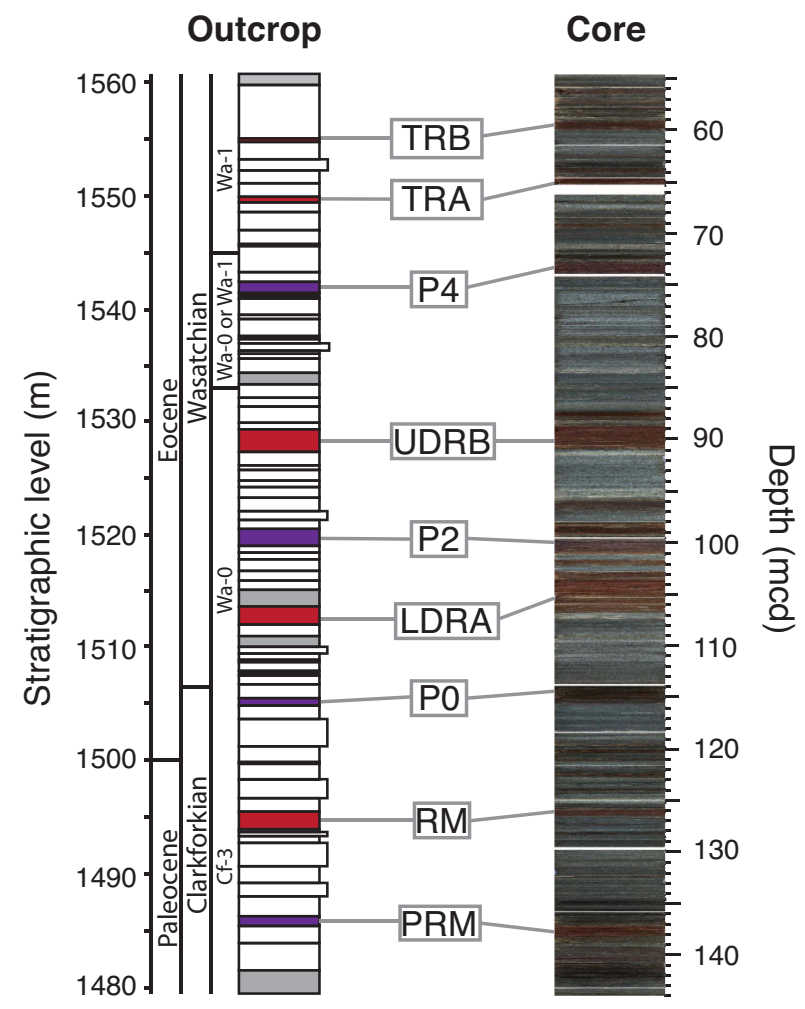

Figure 3: Correlations between outcrop stratigraphy (following Gingerich, 2001) and core stratigraphy. All correlations follow those of Bowen et al. (2015) and were independently confirmed from line scan images and during core sampling for this study. Marker paleosols in outcrop stratigraphy are denoted with red and purple. Marker bed abbreviations are as follows: TRB $=$ Top Red B, TRA $=$ Top Red A, P4 = Purple 4, UDRB = Upper Double Red B, P2 $=$ Purple 2, LDRA $=$ Lower Double Red A, P0 = Purple 0, RM $=$ Red Mudstone, and PRM = Purple Red Mudstone.

subtly different settings across a landscape. These additional lateral profiles were sampled at $10 \mathrm{~cm}$ intervals through all horizons. Notably, no additional detail was derived from the $5 \mathrm{~cm}$ sampling resolution in the original profiles compared with the $10 \mathrm{~cm}$ sampling resolution in the additional profiles, which suggests that $10 \mathrm{~cm}$ resolution is sufficient to capture the important magnetic variability in these paleosols. Samples from correlative paleosols 

${ }_{171}=376$ outcrop, $\mathrm{n}=169$ core) at low $(465 \mathrm{~Hz})$ and high frequency (4650

in the core were acquired at roughly $10 \mathrm{~cm}$ intervals, with occasional minor adjustments to accomodate the availability of sediment core remaining after previous sampling.

Sample preparation and magnetic measurements were performed at the Institute for Rock Magnetism, University of Minnesota. Core and outcrop samples were placed into diamagnetic plastic cubes and were secured using a non-magnetic potassium silicate adhesive. Samples were neither crushed nor homogenized in order to avoid altering the natural grain size distribution of the paleosols, which can significantly impact grain size dependent magnetic properties (for example, anhysteretic remanent magnetization). However, multiple individual mudstone pieces were included in each cube and highly mottled and/or depleted rhizosphere zones were avoided during sampling. Each specimen underwent all of the magnetic measurements described below unless otherwise indicated. All B-horizon mean values come from individual paleosol profiles and are a mean of all B-horizon specimens measured for a particular profile and measurement. Comparisons between core and outcrop are between core profiles and individual outcrop profiles, even where an individual paleosol layer was collected from multiple outcrop profiles.

\subsection{Magnetic Susceptibility}

In-phase magnetic susceptibility $(\chi)$ was measured on all specimens (n 
$\mathrm{Hz}$ ) using a Magnon variable frequency susceptibility meter in an alternating current (AC) field of $300 \mathrm{Am}^{-1}$. Reported values for individual specimens represent the mean of 4 replicate low frequency measurements. The frequency dependence of $\chi$ is commonly used in environmental magnetic studies of soils and paleosols as an indicator of the presence of ultrafine grained magnetite/maghemite that is close to the grain size threshold of stable single domain (SSD) and superparamagnetic (SP) magnetite (Dearing et al., 1996). Frequency dependence of susceptibilty $\left(\chi_{f d} \%\right)$ was calculated, where $\chi_{f d} \%=\left[\left(\chi_{465 H z}-\chi_{4650 H z}\right) / \chi_{465 H z}\right] \times 100 \%$.

\subsection{IRM and $A R M$}

An isothermal remanent magnetization $(I R M)$ and an anhysteretic remanent magnetization $(A R M)$ were imparted to all specimens ( $\mathrm{n}=376$ outcrop, $\mathrm{n}=169$ core). For each specimen, $A R M$ was imparted in a peak alternating field (AF) of $100 \mathrm{mT}$ in the presence of a weak direct current (DC) bias field of $50 \mu \mathrm{T}$. The $A R M$ susceptibility $\left(\chi_{A R M}\right)$, was calculated by dividing the measured $A R M$ by the bias field. IRMs were imparted using three pulses of a $100 \mathrm{mT}$ direct current field in a pulse magnetizer. IRM and $A R M$ remanences were measured immediately using a 2G Enterprises 760-R SQUID magnetometer within a shielded room with a background field of less than $100 \mathrm{nT}$. 


\subsection{Hysteresis Properties}

Hysteresis loops and backfield remanence curves were measured on a subset of samples from each paleosol profile $(n=170$ outcrop, $n=70$ core) using a Princeton Measurements Corporation Micromag vibrating sample magnetometer (VSM) at room temperature in fields up to 1 Tesla. Saturation magnetization $\left(M_{s}\right)$, saturation remanent magnetization $\left(M_{r s}\right.$; equivalent to saturation $I R M$, or $S I R M)$, coercivity $\left(B_{c}\right)$, and coercivity of remanence $\left(B_{c r}\right)$ are all derived from hysteresis and backfield measurements (see overview in Maxbauer et al. 2016). The remanence held by magnetic minerals between $100 \mathrm{mT}$ and $1 \mathrm{~T}$ is referred to as the "hard" IRM, or HIRM, where $H I R M=0.5 \times\left(S I R M+I R M_{-100 m T}\right)$.

\subsection{Coercivity Unmixing}

For all B-horizon specimens where backfield curves were collected, we calculated coercivity distributions using the absolute value of the first derivative of backfield remanence. In order to identify the individual components that contribute to remanence at various field strengths up to $1 \mathrm{~T}$ we used a curvefitting program developed in the $\mathrm{R}$ programming language (available on-line at http://www.irm.umn.edu/maxunmix), which is based on similar methods to those of Kruiver et al. (2001), Heslop et al. (2002), and Egli (2003). Our method uses skew-normal distributions that can be described with a mean coercivity $\left(B_{h}\right)$, a dispersion parameter $(D P$, equivalent to one standard 

232

deviation in log-space), and a skewness factor $(S)$. Modeled distributions for each component can be added linearly to approximate the measured coercivity distribution (on a coercivity versus log-field diagram). The total contribution of each component to the $S I R M$ is calculated as the integrated area under each model component divided by the total integrated area underneath the coercivity distribution across the range of field values covered by the magnetization data (i.e., there is no extrapolation for unsaturated backfield curves).

Initial optimization of user-defined fitting was automated to minimize the residual sum squared (RSS) between the measured and modeled coercivity distributions. Error in the model is accounted for by a Monte Carlo style resampling routine. For each iteration, the program randomly drops $5 \%$ of the original magnetization data prior to deriving coercivity distributions. The resampled coercivity distributions are then fitted using the initial optimized fits (achieved using the entire magnetization dataset), which are resampled assuming a $2 \%$ error in their initial value. Optimization is again automated for each resampled coercivity distribution and the reported models for coercivity distributions and individual components are the mean of 100 resamples with error envelopes representing the 2.5 and 97.5 percentiles (95\% confidence interval). 


\subsection{Temperature dependent measurements}

Temperature dependent measurements were conducted on a small subset of specimens in order to more definitively identify magnetic minerals within the studied paleosols. Room temperature saturation IRM (RT-SIRM) was measured using a Quantum Design Magnetic Properties Measurement Systems (MPMS). Specimens were first given an IRM of $5 \mathrm{~T}$ at room temperature $(300 \mathrm{~K}$; followed by a smaller $I R M$ of $2.5 \mathrm{~T}$ along the same axis to minimize recoil within the MPMS system). Remanence was then measured during cooling to $20 \mathrm{~K}$ and subsequent warming back to room temperature. RT-SIRM curves reveal remanence loss at diagnostic transition temperatures (e.g., the Verwey and Morin transitions for magnetite and hematite, respectively). However, the Morin transition of hematite is often suppressed in natural soils and sediments due to defects and aluminum substitution (e.g., Maher et al., 2004). In order to confirm the presence of hematite, we measured backfield remanence curves with saturating fields of $1.5 \mathrm{~T}$ at 25 ${ }^{\circ} \mathrm{C}(298 \mathrm{~K})$ and $130{ }^{\circ} \mathrm{C}(403 \mathrm{~K})$. The high temperature backfield curve was measured above the Néel temperature of goethite $\left(125^{\circ} \mathrm{C}\right)$ and all high-field remanence in this experiment is attributed to hematite. 


\section{Results}

\subsection{Magnetic Susceptibility, ARM, and IRM}

Bulk $\chi$ within core and outcrop paleosol profiles range from $5 \times 10^{-8}$ to $25 \times 10^{-8} \mathrm{~m}^{3} \mathrm{~kg}^{-1}$, which is consistent with values reported for ancient paleosols (Figure 4A and Figure S1; Rankey and Farr, 1997; Cogoini et al., 2001; Retallack et al., 2003; Tramp et al., 2004; Morón et al., 2013). Frequency dependence of susceptibility for the paleosols studied here was low $(<2 \%)$ and inconsistent, which suggests either the absence of ferrimagnetic minerals in the SP state in these soils prior to fossilization, or their poor preservation. $A R M$ (Figure $4 \mathrm{C}$ and Figure $\mathrm{S} 2$ ) and $I R M$ (Figure $4 \mathrm{E}$ and Figure S3) both have similar trends within and amongst paleosol profiles in core and outcrop. $A R M$ ranges from $3 \times 10^{-6}$ to $30 \times 10^{-6} \mathrm{Am}^{2} \mathrm{~kg}^{-1}$ and $I R M$ values are between $1 \times 10^{-4}$ and $15 \times 10^{-4} \mathrm{Am}^{2} \mathrm{~kg}^{-1}$ (Figure S2 and S3, respectively). Vertical profiles of $\chi, A R M$, and $I R M$ variations within paleosols generally do not have systematic magnetic parameter increases within the upper B-horizon, as is commonly observed in modern soils (see Figures S1-S3; Maher, 1998; Geiss et al., 2008; Lindquist et al., 2011). We note that the A-horizon for these paleosols has been mostly stripped off, which likely contributes, in part, to the lack of an enhanced magnetic signature. In nearly all instances, $A R M$ and IRM values for B-horizons are greater than the underlying C-horizons upon which the soil developed (Figures S1-S3). Notably, the $\chi, A R M$, and $I R M$ 
data are not offset systematically between core and outcrop for equivalent paleosol B-horizons (Figure 4A, C, and E; p > 0.25 for all paired t-tests and Wilcoxon Signed-Rank Tests, which supports no difference between core and outcrop records).

\subsection{Hysteresis Properties}

Example hysteresis loops and backfield curves for both low and high coercivity end member specimens are shown in Figure 5, All hysteresis loops are wasp-waisted to varying extents, which indicates mixed magnetic mineral assemblages (Roberts et al., 1995; Tauxe et al., 1996). Mean B-horizon $B_{c}$ varies between 10 and $160 \mathrm{mT}$ with $B_{c r}$ values ranging from 80 to $500 \mathrm{mT}$. Both $B_{c}$ and $B_{c r}$ are considerably higher in paleosol B-horizons compared with underlying C-horizons (Figures S6 and S7). Similar to the patterns observed for the $\chi, A R M$, and $I R M$ data, despite variations amongst various outcrop and core profiles (Figures S6 and S7) for equivalent paleosol layers, there is no consistent difference in bulk $B_{c}$ or $B_{c r}$ between core and outcrop (Figure 4D and 4F; p > 0.3 for all paired t-tests and Wilcoxon SignedRank Tests). By contrast, $M_{r}$ and HIRM for B-horizons sampled from core sediments are consistently lower than those observed in equivalent outcrop B-horizons (Figure 6, $\mathrm{p}<0.05$ for all paired t-tests and Wilcoxon SignedRank Tests, which indicate that outcrop values are significantly greater than core values). On average mean B-horizon $M_{r}$ increases by $23 \%$ in outcrops 

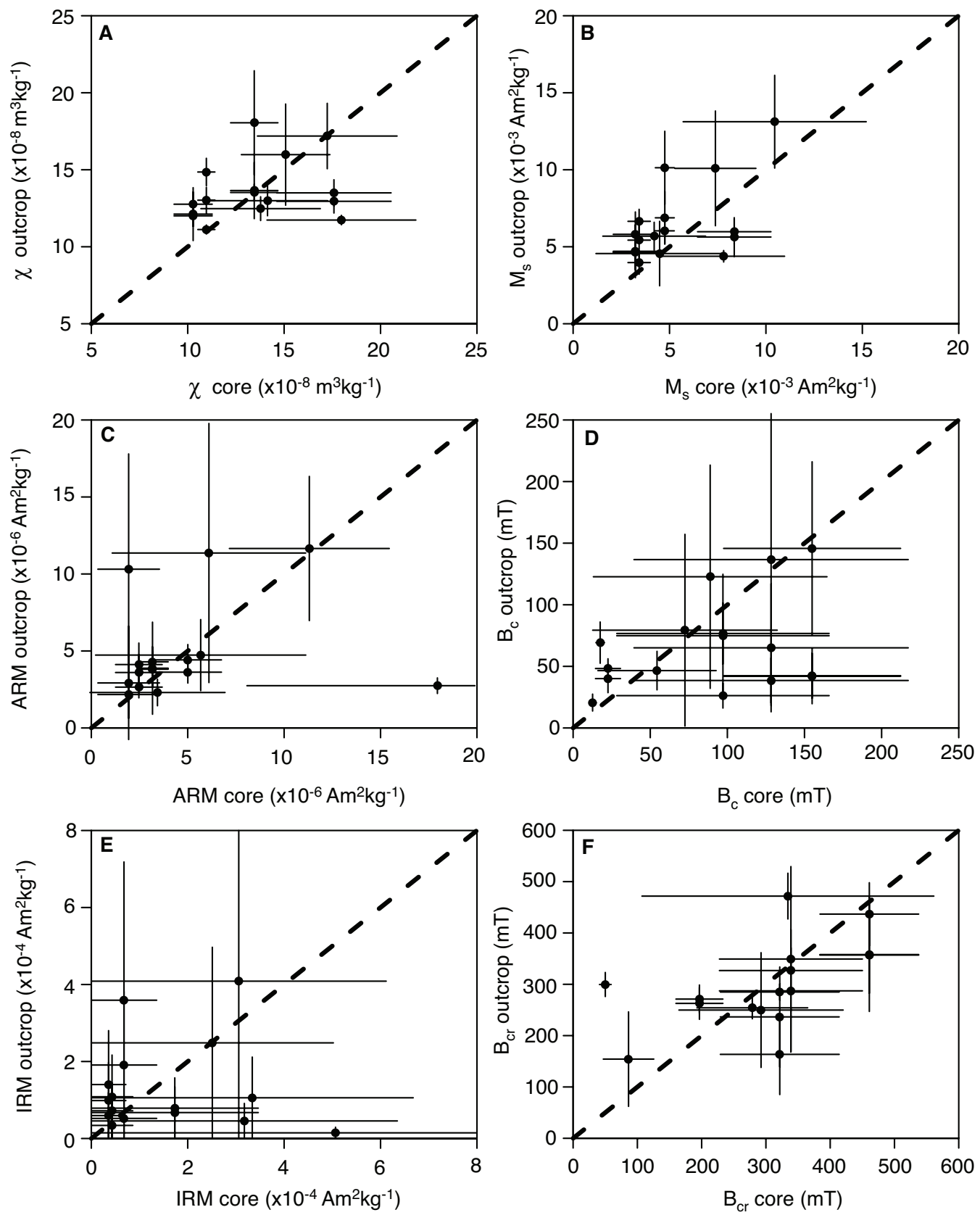

Figure 4: Comparison of magnetic parameters for equivalent B-horizons preserved in core and outcrop. The data are expected to fall on 1-to-1 lines (dashed lines in all plots) if there is no difference between core and outcrop data. All data points represent mean B-horizon values with error bars at \pm 1 standard deviation. For all parameters there is high variability, but no significant difference between outcrop and core values (all p-values $>0.25$ for a paired t-test and Wilcoxon Signed-Rank Test). 
and HIRM increases by $41 \%$ in equivalent outcrop profiles. B-horizon values of $M_{s}$ within both cores and outcrop profiles range between $4 \times 10^{-3}$ and $12 \times 10^{-3} \mathrm{Am}^{2} \mathrm{~kg}^{-1}$. Although there is mostly a similar trend of increased $M_{s}$ in outcrops relative to core equivalents, this effect is not as consistent as $M_{r}$ and HIRM observations (compare Figure $4 \mathrm{~B}$ with Figure $6 \mathrm{C}$ and $6 \mathrm{D}$ ).

\subsection{Coercivity Unmixing}

Analysis of coercivity distributions of B-horizon samples revealed that the remanent magnetization is principally held by two components (e.g., Figure 7A). The low-coercivity component $(L C C)$ is characterized by average $B_{h}$ values between 1.3 and $2.1(20-126 \mathrm{mT})$ and $D P$ between 0.3 and 0.8 (Figure 7B). The average $B_{h}$ and $D P$ observed for the $L C C$ in both core and outcrop paleosols are generally higher than values typically reported in the literature for pedogenic magnetite (green squares in Figure 7B; Egli, 2004; Geiss et al., 2008; Lindquist et al., 2011). The degree of skewness for the $L C C$ is pronounced $(0.46-0.76$; upper and lower quartiles; note that $S=1$ is equivalent a normal distribution; see Table S5), with a consistent low-field tail observed. There is generally no consistent deviation between the $L C C$ preserved in the core compared to the $L C C$ preserved in equivalent outcrops (consistent $B_{h}$ and contribution to remanence, all p-values $\geq 0.05$ ).

The $H C C$ in both core and outcrops is characterized by $B_{h}$ values between 2.4 and $3.0(251-1000 \mathrm{mT})$ with $D P$ consistently between 0.2 and 0.7 


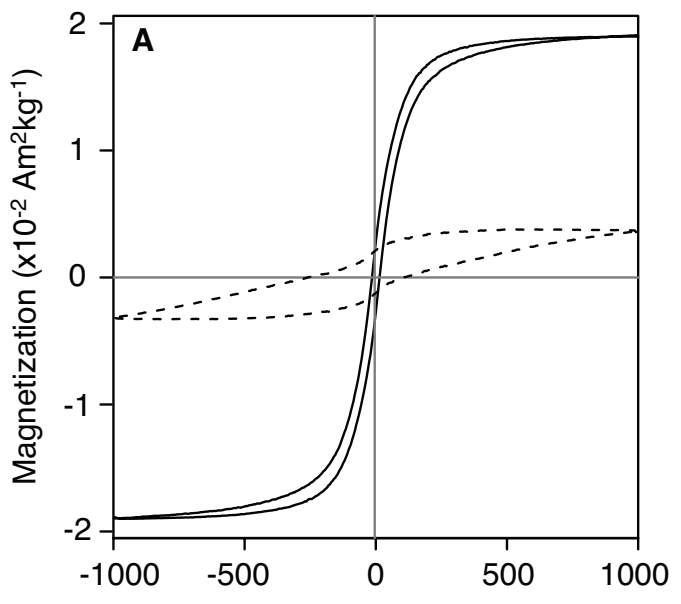

Field (mT)

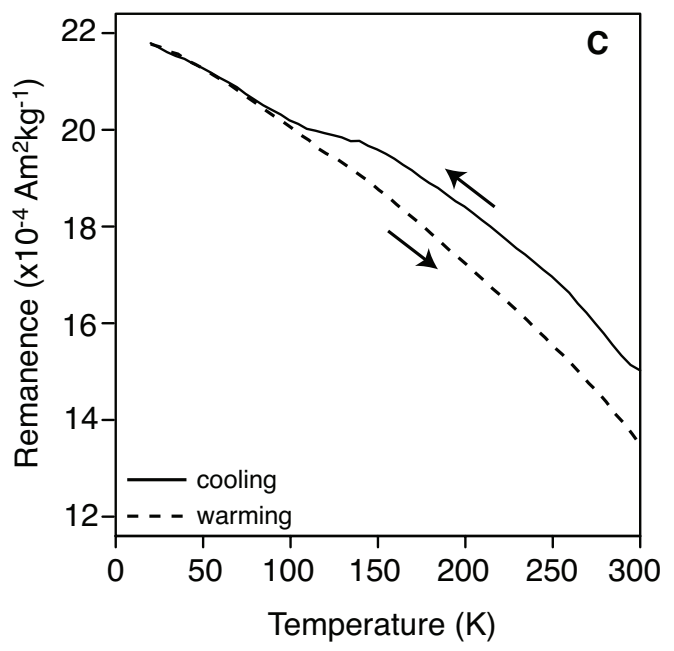

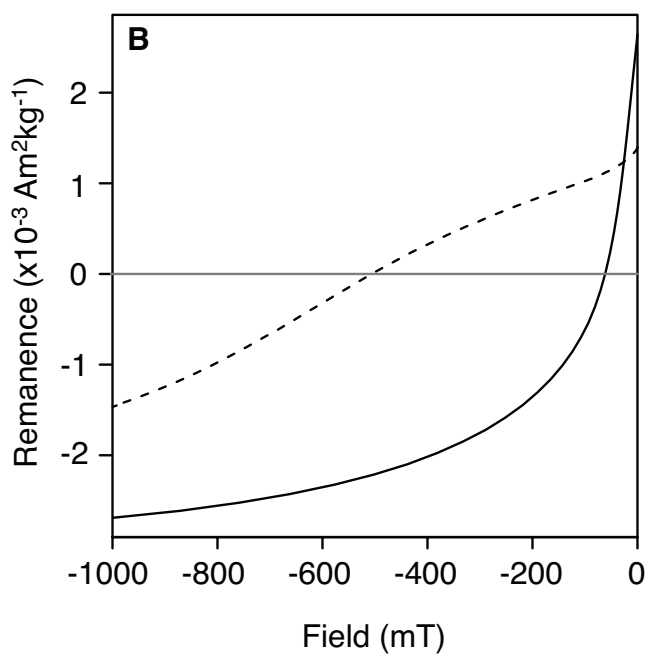

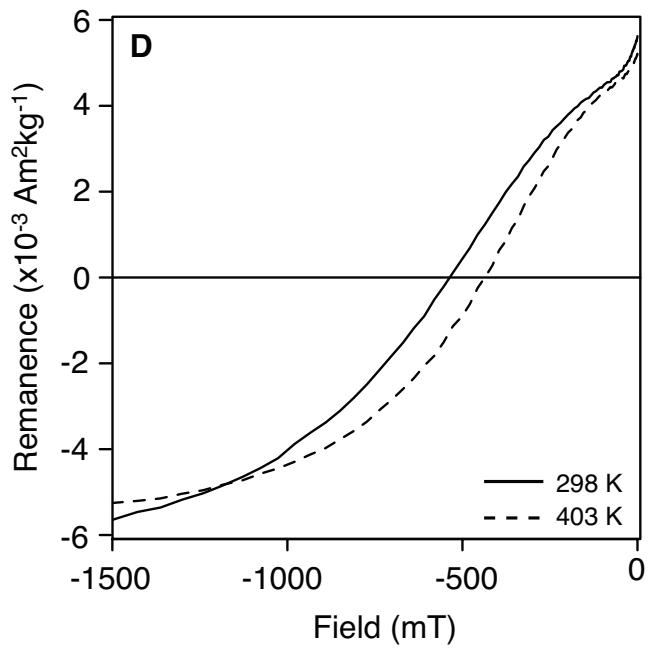

Figure 5: A-B.Example hysteresis loops (A) and backfield demagnetization curves (B). The solid line is from specimen PCB-01-LDRA-070 and represents a relatively lowcoercivity but strongly magnetic end member (common in the large red paleosols LDRA and UDRB). The wasp-waistedness of this loop is likely due to a mixed magnetic assemblage of 'hard' and 'soft' magnetic minerals. The dashed line for specimen P2-155 represents an example of a more weakly magnetic, but higher-coercivity specimen more commonly observed in purple paleosols. C. A room-temperature SIRM for specimen PCB-03-PRM-100 undergoes a loss of magnetization across the Verwey transition of magnetite (110 K for pure magnetite) and an overall remanence increase on cooling that indicates likely contributions from goethite (Maher et al. 2004). D. Backfield curves measured on specimen PCB-01-UDRB-145 at room temperature (solid line) and at 403 $\mathrm{K}\left(130{ }^{\circ} \mathrm{C}\right.$; dashed line), above the Néel temperature of goethite. The high temperature backfield curve still carries a majority of the room temperature remanence, which suggests that hematite and not goethite is the primary high field remanence carrier in these specimen. 

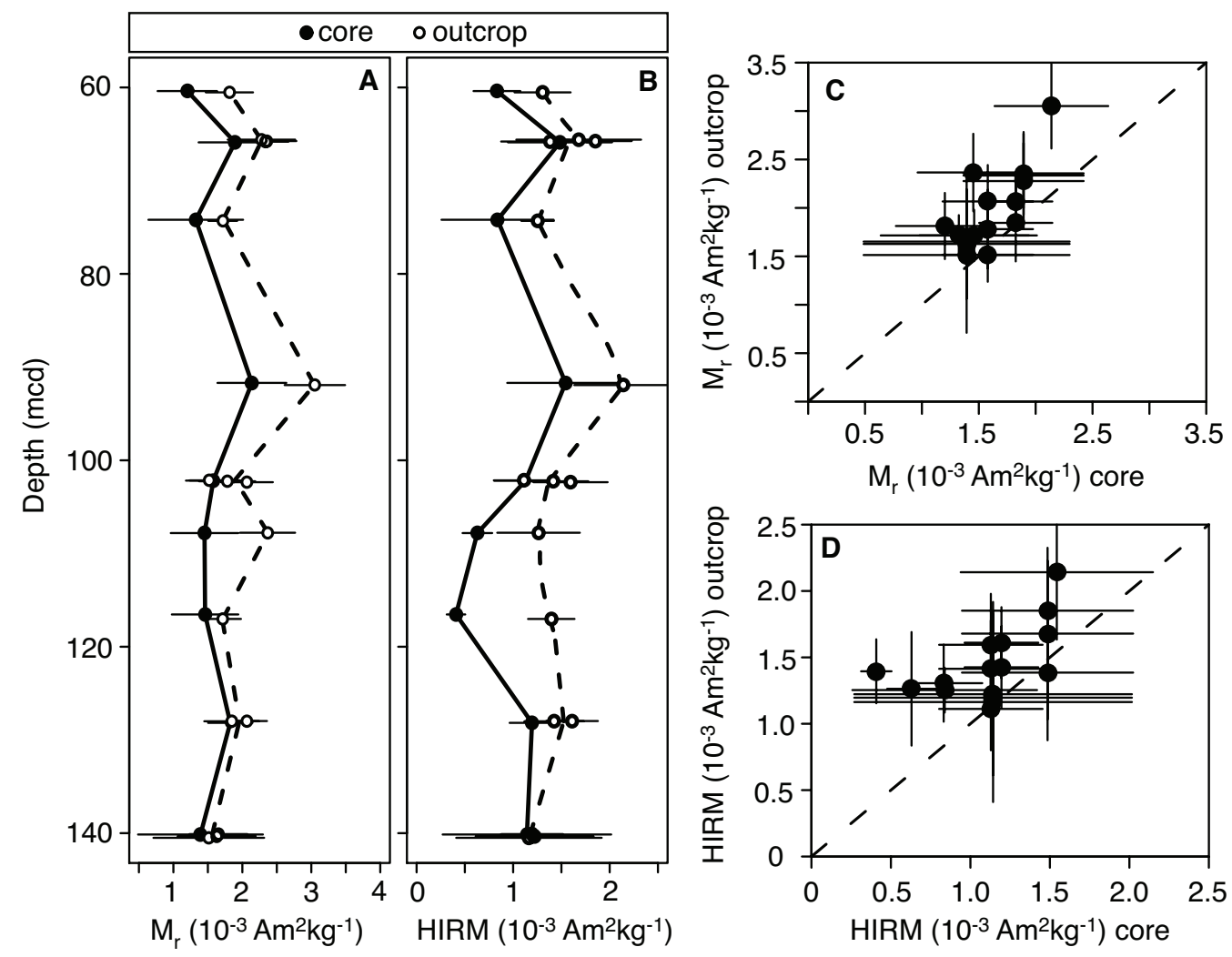

Figure 6: A-B. Mean B-horizon remanent magnetization $\left(M_{r}, \mathrm{~A}\right)$ and 'hard' isothermal remanent magnetization (HIRM, B) for equivalent paleosol layers in the core (closed symbols, solid line) and outcrop (open symbols, dashed line). C-D. Cross plots of $M_{r}$ (C) and HIRM (D) highlight the observed increase in both magnetic parameters within outcrops compared with the equivalent paleosol preserved in the core. All error bars are \pm 1 standard deviation. For both HIRM and $M_{r}$, there is a significant $(\mathrm{p}<0.05$; for both paired t-test and paired Wilcoxon Signed-Rank Test) increase observed in outcrops relative to the equivalent core. 
(Figure 7B). Skewness in the $H C C$ is less pronounced, with a median value for $S$ of 1.01 (0.96, 1.04; upper and lower quartiles). The remanence held by the $H C C$ is consistently higher in outcrops ( $~ 46 \%$ increase in outcrop relative to core) and has a consistent pattern with observations made from $H I R M$ and $M_{r}$ values. The observed $B_{p}$ and $D P$ of the $H C C$ reported here are consistent with work from a previous study that identified high-coercivity components with similar $B_{h}$ and $D P$ as hematite (Hyland et al., 2015, note that they used non-skewed normal distributions).

\subsection{Temperature Dependent Measurements}

RT-SIRM undergoes a characteristic decrease just prior to $110 \mathrm{~K}$, which is diagnostic of the Verwey transition of magnetite (or partially oxidized magnetite), and a nearly 2-fold increase in remanence on cooling, which indicates contribution from goethite and/or fine-grained hematite (Figure 5 C; Maher et al., 2004). Previous work has shown that both hematite and goethite are present in Bighorn Basin paleosols based on XRD data (note that magnetite is too scarce volumetrically to be detected by XRD; Kraus and Hasiotis, 2006). The Morin transition is absent from the RT-SIRM measured in this study (similar to some modern red soils; Maher et al., 2004). However, the presence of hematite as the dominant high-field remanence carrier is inferred by comparison of backfield demagnetization curves measured at room temperature $\left(25^{\circ} \mathrm{C} ; 298 \mathrm{~K}\right)$ and at $130{ }^{\circ} \mathrm{C}(403 \mathrm{~K})$. The majority of high-field 
remanence (> $100 \mathrm{mT}$ ) in specimen PCB-01-UDRB-145 remains when backfield remanence is monitored above the Néel temperature of goethite $\left(125^{\circ} \mathrm{C}\right.$; above which goethite carries no remanence), which indicates that hematite is the dominant 'so-called' antiferromagnetic phase in these paleosols (Figure $5 \mathrm{D})$

\section{Discussion}

Our results comprise arguably the most complete magnetic dataset for an ancient (pre-Quaternary) non-loessic paleosol sequence. Furthermore, detailed correlations between core and outcrop, for the first time, allow direct comparison of the magnetic properties of weathered and unweathered sections of the same paleosols. Our dataset allows us to directly address two fundamental assumptions that must be made when applying magnetic paleoprecipitation proxies to ancient paleosols: (1) surficial weathering of outcrops does not impact magnetic mineral preservation, and (2) magnetic minerals retain information about paleoprecipitation. We address these two assumptions below.

\subsection{Magnetic mineral resistance to surficial weathering}

The observed increase in $M_{r}, H I R M$, and the remanence held by the $H C C$ all indicate that there is a consistent remanence increase for high coercivity minerals in outcrop paleosols relative to their core equivalents (Figure 


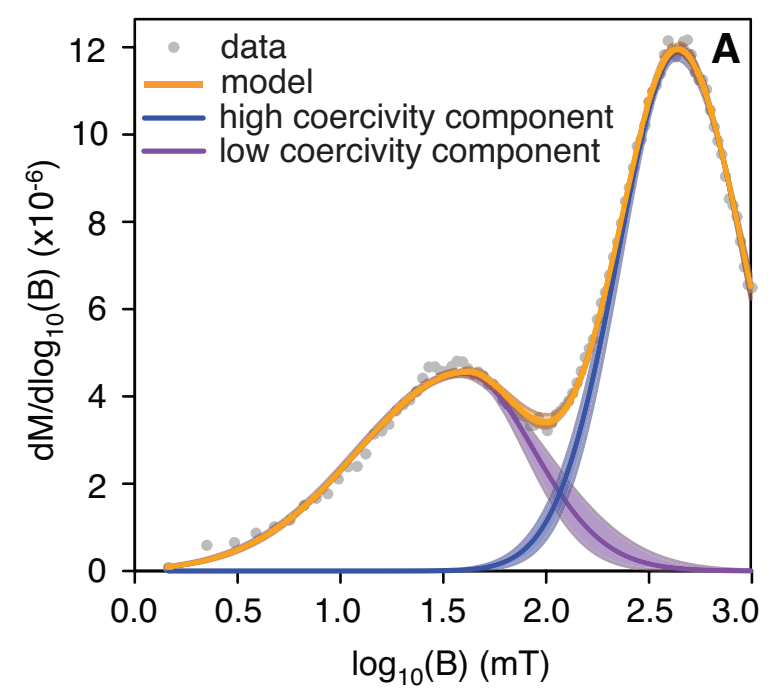

modern

B

pedogenic magnetite

paleosol (core) paleosol (outcrop)

$\bigcirc$ LCC OHCC $\diamond$ LCC $\diamond \mathrm{HCC}$

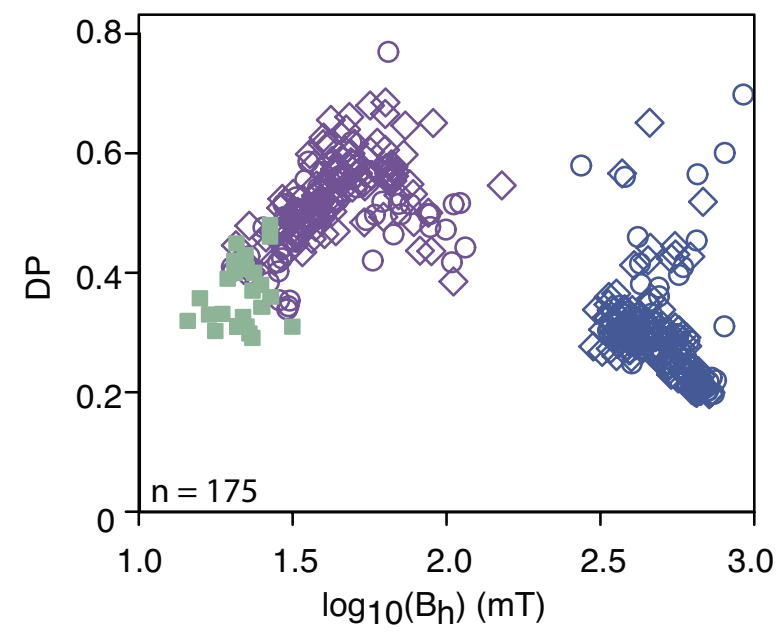

Figure 7: A. Example of backfield coercivity spectra (data shown in grey symbols) with the modeled best fit (orange). Data were fitted using a two-component model with a high (blue) and low (purple) coercivity component. Shaded envelopes for component distributions and model indicate an approximate $95 \%$ confidence interval. Data shown are from core specimen UDRB-100. B. Cross plot of the dispersion parameter $(D P)$ and mean coercivity $\left(B_{h}\right)$. Examples of modern pedogenic magnetite (green squares) are displayed with data from Egli (2004), Geiss and Zanner (2006), Lindquist et al. (2011), and Bourne et al. (2015). Note that Bourne et al. (2015) presented data recovered from a speleothem, but were interpreted to represent partially oxidized pedogenic magnetite. Data for B-horizon specimen from core and outcrop are shown in purple (low-coercivity component; $L C C$ ) and blue (high-coercivitygemponent; $H C C$ ). 
6). Notably, this increase is not observed in HIRM if calculated using a backfield of $300 \mathrm{mT}$ instead of $100 \mathrm{mT}$. This indicates that the principal increase in remanence is acquired in magnetic fields of $100-300$ mT. Remanence acquired at these field strengths is most likely held by either partially oxidized magnetite/maghemite or by low-coercivity, ultrafine-grained hematite (Liu et al. 2002, 2007; Özdemir and Dunlop, 2014). We propose that the increase in both $M_{r}$ and HIRM that is observed in outcrops is due to formation of ultrafine $(25-100 \mathrm{~nm})$ pigmentary hematite within outcrops that formed via oxidation associated with surficial weathering.

Similar to observed color changes in the upper 25 meters of sediment cores recovered by the BBCP, visual inspection suggests that the outcrop paleosols have a more intense red coloration. Comparison of the semi-quantitative redness index (a*; calculated from reflectance spectral data; Abdul Aziz et al., 2008; Bowen et al., 2015) for outcrop marker bed paleosols compared with their core counterparts indicates a consistent and significant redness increase within outcrops (Figure 8, p $<0.003$ for both paired t-test and Wilcoxon Signed-Rank Test). Fine-grained hematite acts as a red pigment in a variety of sedimentary settings (Chen et al., 2010). Furthermore, the magnetic properties of ultrafine pigmentary hematite are consistent with the observed variations noted here between core and outcrop paleosols. Grain sizes associated with pigmentary hematite in paleosols on the Chinese Loess Plateau are 
roughly $50-100 \mathrm{~nm}$ (Chen et al., 2010), which corresponds roughly to $B_{c}$ values on the order of $10-200 \mathrm{mT}$ (Özdemir and Dunlop, 2014). This suggests that ultrafine grained hematite, if present, would acquire $M_{r}$ beginning at low fields $(100 \mathrm{mT})$ and could be the primary source of the anomalously high $M_{r}$ and HIRM in outcrops.

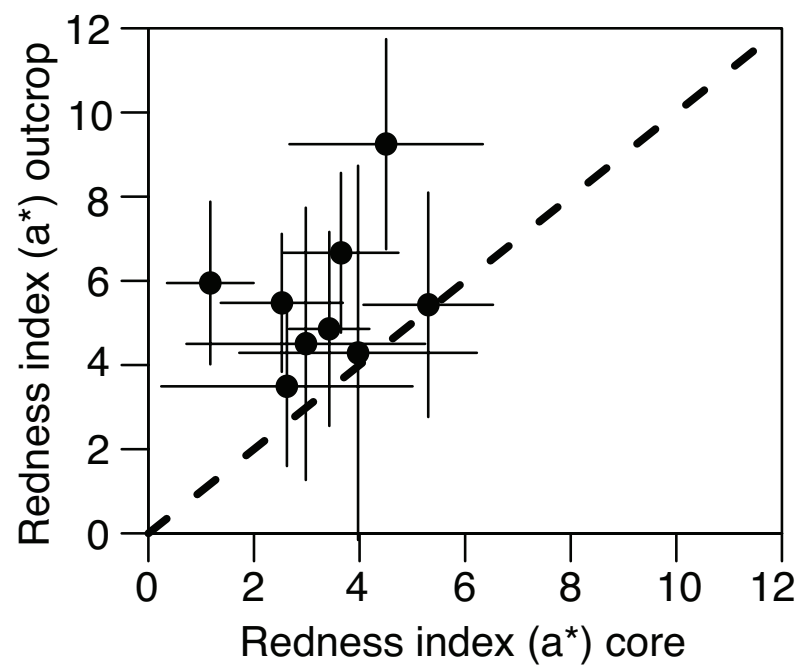

Figure 8: Redness Index $(a *)$ data from paleosol B-horizons at Polecat Bench. The dashed line indicates the 1:1 relationship. Note that in each paleosol, the mean a* value of the outcrop is higher than the equivalent paleosol layer sampled from core. Redness data for the core are from Bowen et al. (2015) and are from Abdul Aziz et al. (2008) for the outcrop.

Pigmentary hematite formation within outcrops could result from either transformation of low-coercivity magnetite/maghemite, alteration of preexisting clay minerals, or dehydration of goethite to hematite. Transformation of low-coercivity ferrimagnets into ultrafine hematite would likely be associated with a paired decrease in $\chi, A R M$, and $I R M$ values for outcrops. 
This is not consistent with our data (Figure 4), where despite deterioration of the low-coercivity minerals, their contribution to remanence is not significantly different between core and outcrop (e.g., remanence held by the $L C C$, $\mathrm{p} \geq 0.38$ for paired t-test and paired Wilcoxon Signed-Rank Test). Alteration of iron-bearing clay minerals is associated with pigmentary hematite formation within paleosols on the Chinese Loess Plateau (Chen et al., 2010) and remains a possibility in the Bighorn Basin sequence, where clay minerals are abundant within B horizons ( $\sim 30$ weight \%; Kraus et al., 2015).

Dehydration of goethite to hematite is a proposed mechanism for the post-burial reddening of red beds and paleosols (Retallack, 1991). Previous work mostly discounted this mechanism for paleosols in the Bighorn Basin on the basis that the effect should be pervasive and would erase the complex color assemblages that preserve pedogenic mottling in these deposits Kraus and Hasiotis, 2006). Dehydration of fine-grained goethite in these paleosols into hematite would be consistent with observed increases in $M_{r}, H I R M$, and increased remanence held by $H C C$ in outcrops. Secondary hematite formation in this system may also explain the strong normal polarity overprint that has been observed in paleomagnetic studies from the Bighorn Basin (e.g., Clyde et al., 2007). However, we cannot make a definitive conclusion about the dehydration mechanism because our saturating fields (1 T) were far too low to efficiently magnetize goethite within these sediments (Rochette 
et al., 2005). The production of secondary hematite as a weathering product in outcrop paleosols, regardless of the exact geochemical pathway, challenges the assumption that magnetic minerals within paleosols, and outcrops of sedimentary rocks in general, remain unaffected by surface weathering.

\subsection{Relationships between magnetic minerals and precipitation}

Whether pedogenic magnetic mineral assemblages are preserved in ancient paleosols remains a fundamental question when applying magnetic paleopreciptiation proxies to ancient systems. As discussed above, it appears that surficial weathering of outcrops results in authigenic pigmentary hematite formation. The presence of non-pedogenic hematite in outcrop paleosols has considerable implications for the application of $G / H$ proxies Hyland et al. 2015; Long et al. 2011). Additional hematite will act to decrease the $G / H$ ratio and cause MAP estimates to be biased to lower values. Authigenic hematite formed via surficial weathering may help to explain $G / H$ based MAP estimates that are drier than other geochemical and paleobotanical methods (Hyland et al., 2015; Hyland and Sheldon, 2016). Accordingly, we suggest that $G / H$ MAP estimates be viewed as minimum constraints.

Parameters that remain unaffected by weathering (e.g., $\chi, A R M, I R M$ ) are generally controlled by low coercivity ferrimagnetic minerals (magnetite and maghemite). However, these parameters have considerable variability and lack characteristics of a magnetically enhanced profile similar to modern 
soils (Maher, 1998; Geiss and Zanner, 2006; Geiss et al., 2008; Lindquist et al., 2011). This suggests that diagenetic processes, independent of weathering, have altered the low coercivity ferrimagnetic mineral population. However, relative enhancement ratios (as used in modern calibrations with MAP; Geiss et al., 2008) for the Polecat Bench section are comparable with those of some modern soils and appear to correlate with independent MAP estimates from the CALMAG geochemical weathering index (Figure 9 and Table 1 , Geiss et al. 2008; Kraus et al., 2015). Correlations between MAP and enhancement ratios are generally higher for the core sediments compared with outcrop correlations, which may suggest that more variability is introduced via surficial weathering to outcrops that are not observed in core sediments (Table 1). However, significant $(\mathrm{p}<0.05)$ and moderately strong $\left(\mathrm{R}^{2} \geq 0.46\right.$; Table 1$)$ correlations still exist in the outcrop section, which suggest that despite small influences from surficial weathering qualitative climatic information will still be preserved by the magnetic mineral assemblage.

Using empirical transfer functions to produce quantitative MAP estimates from the enhancement ratios shown in Figure 9 requires the assumption that the ratio has remained unchanged throughout the geologic history of a paleosol (from burial of the original soil to exposure as outcrop or recovery from core). Magnetic enhancement in modern soils is principally driven by pedogenic production of SSD and SP magnetite/maghemite in the upper 


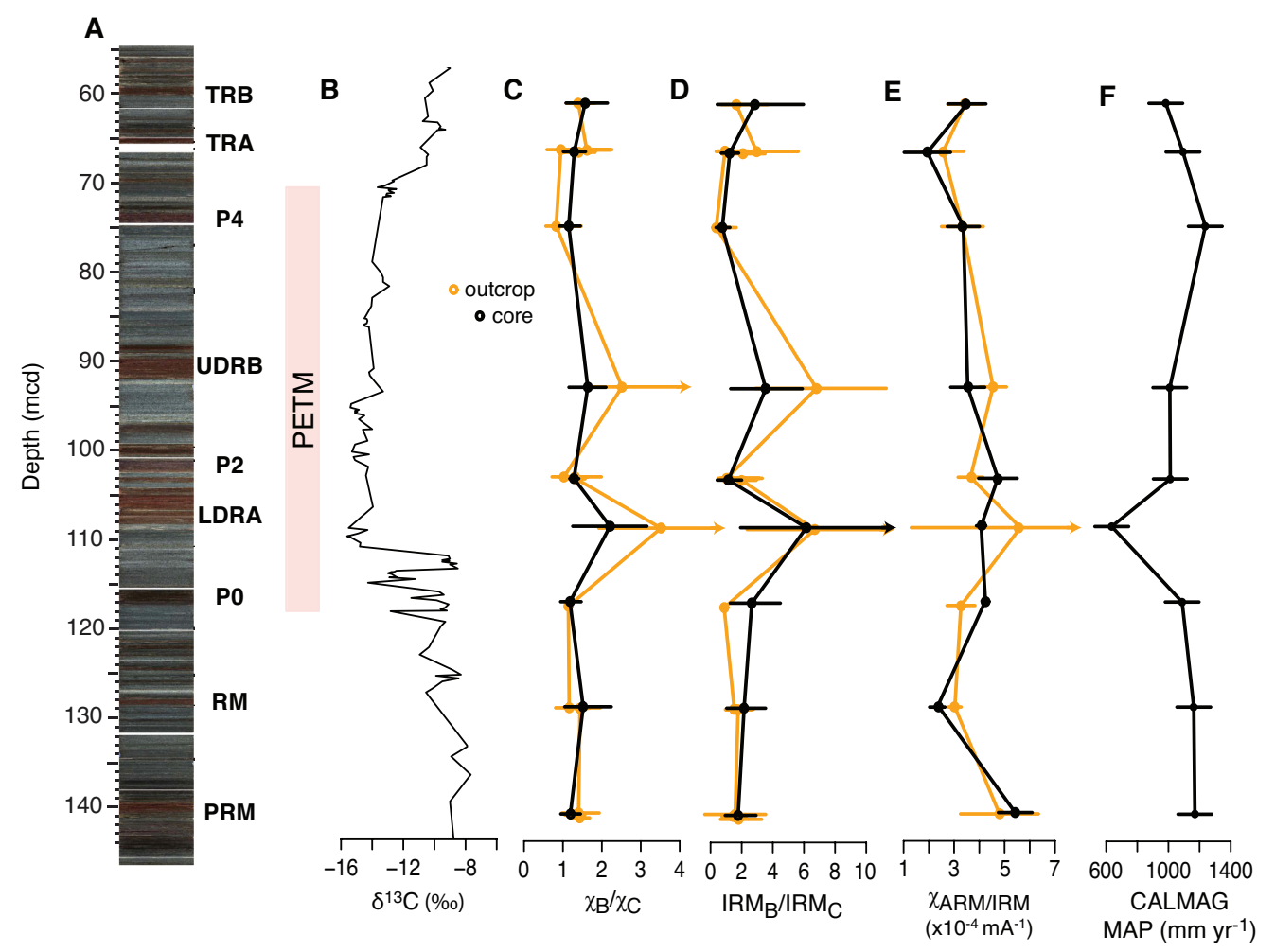

Figure 9: Mean B-horizon magnetic enhancement parameters for marker bed paleosols at Polecat Bench. A. Line-scan image of core stratigraphy and location of marker paleosols in the core. B. Carbon isotopic composition of pedogenic carbonates is shown to highlight the onset, main body, and recovery of the PETM (data from Bowen et al., 2015). C-D. B-horizon enhancement ratios for magnetic susceptibility $(\chi, \mathrm{C})$ and isothermal remanent magnetization $(I R M, \mathrm{D})$. For each magnetic parameter the mean B-horizon value was normalized to the mean value of the C-horizon. B-horizon means for enhancement ratios were calculated using "enhanced" specimen, indicated in bold in Tables S1 and S3, similar to the approach taken by Geiss et al. (2008). Error bars approximate the 95\% confidence interval and were calculated as the 2.5 and 97.5 percentiles of a Monte Carlo style resampling using $\mathrm{B}$ and $\mathrm{C}$ horizon means and standard deviations assuming a normal distribution. E. B-horizon mean ratio of susceptibility of anhysteretic remanent magnetization to $I R M\left(\chi_{A R M} / I R M\right)$. F. CALMAG mean annual precipitation (MAP) data are from Kraus et al. (2015) and represent independent estimates of MAP derived from the bulk geochemistry of the same marker bed paleosols (both core and outcrop). Note that in cases where arrows are on the ends of error bars the error bars were reduced to avoid overlap with adjacent panels. 
Table 1: Correlation of magnetic parameters with mean annual precipitation (MAP) and B-horizon thickness. ${ }^{\text {a. }}$

\begin{tabular}{|c|c|c|c|c|}
\hline \multirow[t]{2}{*}{ Parameter } & \multicolumn{2}{|c|}{ Core } & \multicolumn{2}{|c|}{ Outcrop } \\
\hline & $M A P$ & Thickness & $M A P$ & Thickness \\
\hline$\chi_{B} / \chi_{C}$ & $0.79(0.0014)$ & $0.02(0.72)$ & $0.64(0.0002)$ & $0.21(0.08)$ \\
\hline$I R M_{B} / I R M_{C}$ & $0.79(0.0014)$ & $0.04(0.60)$ & $0.46(0.0040)$ & $0.30(0.03)$ \\
\hline$A R M_{B} / A R M_{C}$ & $0.55(0.0227)$ & $0.05(0.57)$ & $0.46(0.0037)$ & $0.30(0.03)$ \\
\hline$\chi_{A R M} / I R M$ & $0.03(0.68)$ & $0.23(0.19)$ & $0.12(0.20)$ & $0.07(0.31)$ \\
\hline$H I R M$ & $0.08(0.46)$ & $0.03(0.65)$ & $0.001(0.90)$ & $0.05(0.41)$ \\
\hline
\end{tabular}

${ }^{\mathrm{a}}$ Mean B-horizon values are used for each indicated magnetic parameter. MAP data are derived from the geochemical weathering index CALMAG and come from Kraus et al. (2015). $\mathrm{R}^{2}$ values are reported with p-values in parentheses. Significant correlations are highlighted with bold and italics.

soil horizons (Maher, 1998; Geiss et al., 2008; Orgeira et al., 2011). Coercivity spectra (from $A R M$ and $I R M$ experiments) from many modern soils have identified a low-coercivity component that is often referred to as pedogenic magnetite (Figure 7B; Egli, 2004; Geiss et al., 2008; Lindquist et al., 2011). Recovery of a similar low-coercivity component within ancient paleosols would increase confidence in the assumption that observable magnetic enhancement in paleosols is driven by similar processes as in modern soils.

The $L C C$ recovered from analysis of $\mathrm{B}$ horizons in the Bighorn Basin paleosols suggests either a lack of pedogenic magnetite in these soils or alteration of pedogenic magnetite via diagenesis and weathering (Figure 7B). Assuming that magnetite was produced in the original soils during pedogenesis, it is feasible that diagenetic processes increased $B_{p}$ (via partial or complete maghemitization; e.g., van Velzen and Dekkers, 1999, Chen et al., 2005) and $D P$ (by increasing the range of coercivities within the original population of 
grains) of the pedogenic magnetite component. Notably, the average $L C C$ of Bighorn Basin paleosols has this trend for pedogenic magnetite (Figure $7 \mathrm{~B})$ and, therefore, we suggest that the $L C C$ represents partially oxidized pedogenic magnetite.

Magnetic paleoprecipitation proxies based on properties such as $\chi, A R M$, and IRM (likely to be dominated by pedogenic magnetite/maghemite) in empirical relationships with MAP are likely to be compromised by the progressive oxidation of pedogenic magnetite during weathering and diagenesis. For example, the $\chi_{A R M} / I R M$ ratio is used as a direct indicator for pedogenic magnetite in the methods of Geiss et al. (2008); our data indicate no correlation between independent estimates of MAP and $\chi_{A R M} / I R M$ (Table 1: Figure 9E). Enhancement ratios may provide a means to normalize the effects of magnetic mineral oxidation, principally under the assumption that any magnetic minerals present in the parent material experience similar processes. It is encouraging that the magnetic enhancement ratios preserved in the studied Bighorn Basin paleosols are of a similar magnitude to those of modern soils (Geiss et al., 2008). We urge caution in assuming that a similar degree of enhancement in a particular magnetic property suggests equivalence between modern and fossil soils. However, the good agreement between magnetic enhancement ratios and geochemical proxies highlights that magnetic minerals do record at least qualitative information about paleoclimate in the 
484

geologic record.

\section{Conclusions}

Our core-to-outcrop comparison of the magnetic properties of paleosols preserved in the Paleocene-Eocene Willwood Formation of the Bighorn Basin allows us to address two fundamental questions related to the application of magnetic paleoprecipitation proxies in ancient systems. First, we evaluated the effects of surficial weathering on the magnetic minerals preserved in outcrops. Outcrop samples have a consistent and significant increase of $\sim 23 \%$ in $M_{r}$ and $\sim 41 \%$ for HIRM compared with equivalent core samples (Figure 6). This increase is interpreted to be caused by secondary pigmentary hematite $(\sim 25-100 \mathrm{~nm})$ production in outcrops and is supported by similar increases in redness index $(a *)$ within outcrops compared to the studied core (Figure 8). The increase in magnetic remanence within outcrops complicates application of magnetic paleoprecipitation proxies that use the proportion of total remanence held by hematite and goethite to estimate magnetic mineral abundance ratios (Long et al., 2011; Hyland et al., 2015). It may be possible with future work to address this complication by more detailed unmixing analysis to differentiate primary pedogenic hematite from the secondary authigenic hematite that forms in subaerial weathering regimes. In this way it may be possible to remove, or at least account for, this non-pedogenic mag- 
netic mineral phase when applying methods based on high-field magnetic properties (e.g., Long et al., 2011; Hyland et al., 2015). At minimum, the observed increase in HIRM and $M_{r}$ increases the uncertainty in applying these methods and the associated error in MAP estimates derived from them. Attempts to address this uncertainty should be included in future work based on these methods.

Second, we evaluated the possibility that magnetic minerals in ancient paleosols record changes in paleoprecipitation across the PETM. Magnetic enhancement ratios of parameters such as $\chi$ and IRM correlate with independent MAP estimates from geochemical proxies (Figure 9, Table1, Kraus et al. 2015). However, applications of magnetic enhancement proxies are complicated by the fact that the pedogenic magnetite recovered from the Bighorn Basin appears to have been altered during diagenesis (in both core and outcrop), which results in higher mean coercivities and broader coercivity distributions. Additionally, current magnetic precipitation proxies have large uncertainties (Heslop and Roberts, 2013; Maher and Possolo, 2013) even when applied in systems where pedogenic magnetite is not altered by diagenesis. So, while the magnetic mineral assemblage preserves qualitative information about paleoprecipitation, quantitative estimates from empirically derived transfer functions may prove difficult to defend if pedogenic magnetite commonly undergoes alteration during diagenesis. 
Our analysis presents some challenging obstacles for quantitative application of soil magnetism to paleoclimate problems in deep time. However, environmental magnetic information is still preserved in these ancient paleosols (e.g., magnetic enhancement ratios, Figure 9), which suggests their continued promise for magnetic assessment of ancient MAP. In future studies, degradation of pedogenic magnetite should be possible to identify based on comparison of coercivity components to magnetites observed in modern soils as done here. Unfortunately, there is currently no obvious way to identify the presence of non-pedogenic, authigenic hematite in outcrops where comparison to equivalent core sediments is not possible. More detailed studies on pre-Quaternary paleosol sequences combined with expanded studies on modern soils could provide solutions to these complications and allow soil magnetism to become an important tool for reconstructing past climates.

\section{Acknowledgements}

We thank P. Gingerich and H. Abels for providing guidance and expertise during fieldwork, U. Röhl and the Marum staff for logistical support in core sampling, J. Munson for field assistance, and P. Solheid and M. Jackson for providing helpful assistance and discussions. Comments from A. Roberts and an anonymous reviewer helped to improve this manuscript. Funding to DPM for this work was provided by a GSA student research grant, the H.E. 
Wright Paleoecology Fellowship, the Richard C. Dennis Fellowship, and the Stanwood Johnston Fellowship through the University of Minnesota. The Bighorn Basin Coring Project was funded through NSF grant EAR-0958821. This is IRM contribution 1607.

\section{References}

Abdul Aziz, H., Hilgen, F. J., van Luijk, G. M., Sluijs, A., Kraus, M. J., Pares, J. M., Gingerich, P. D., 2008. Astronomical climate control on paleosol stacking patterns in the upper Paleocene-lower Eocene Willwood Formation, Bighorn Basin, Wyoming. Geology 36, 531-534.

Adams, J. S., Kraus, M. J., Wing, S. L., 2011. Evaluating the use of weathering indices for determining mean annual precipitation in the ancient stratigraphic record. Palaeogeography, Palaeoclimatology, Palaeoecology $309,358-366$.

Bourne, M. D., Feinberg, J. M., Strauss, B. E., Hardt, B., Cheng, H., Rowe, H. D., Springer, G., Edwards, R. L., 2015. Long-term changes in precipitation recorded by magnetic minerals in speleothems. Geology 43, 595-598.

Bowen, G. J., Maibauer, B. J., Kraus, M. J., Rohl, U., Westerhold, T., Steimke, A., Gingerich, P. D., Wing, S. L., Clyde, W. C., 2015. Two 
massive, rapid releases of carbon during the onset of the Palaeocene-Eocene thermal maximum. Nature Geoscience 8, 44-47.

Chen, T., Xie, Q., Xu, H., Chen, J., Ji, J., Lu, H., Balsam, W., 2010. Characteristics and formation mechanism of pedogenic hematite in Quaternary Chinese loess and paleosols. Catena 81, 217-225.

Chen, T., Xu, H., Xie, Q., Chen, J., Ji, J., Lu, H., 2005. Characteristics and genesis of maghemite in Chinese loess and paleosols: mechanism for magnetic susceptibility enhancement in paleosols. Earth and Planetary Science Letters 240, 790-802.

Clyde, W. C., Gingerich, P. D., Wing, S. L., Röhl, U., Westerhold, T., Bowen, G., Johnson, K., Baczynski, A. A., Diefendorf, A., McInerney, F., Schnurrenberger, D., Noren, A., Brady, K., 2013. Bighorn Basin Coring Project (BBCP): a continental perspective on early Paleogene hyperthermals. Scientific Drilling 16, 21-31.

Clyde, W. C., Hamzi, W., Finarelli, J. A., Wing, S. L., Schankler, D., Chew, A., 2007. Basin-wide magnetostratigraphic framework for the Bighorn Basin, Wyoming. Bulletin of the Geological Society of America 119, 848859.

Cogoini, M., Elmore, R. D., Soreghan, G. S., Lewchuk, M. T., 2001. Contrast- 
ing rock-magnetic characteristics of two Upper Paleozoic loessite-paleosol profiles. Physics and Chemistry of the Earth, Part A: Solid Earth and Geodesy 26, 905-910.

Dearing, J. A., Dann, R. J. L., Hay, K., Lees, J. A., Loveland, P. J., Maher, B. A., Grady, K. O., Survey, S., Mk, B., 1996. Frequency-dependent susceptibility measurements of environmental materials. Geophysical Journal International 124, 228-240.

Egli, R., 2003. Analysis of the field dependence of remanent magnetization curves. Journal of Geophysical Research 108, 2081.

Egli, R., 2004. Characterization of individual rock magnetic components by analysis of remanence curves. 1. Unmixing natural sediments. Studia Geophysica et Geodaetica 48, 391-446.

Geiss, C. E., Egli, R., Zanner, C. W., 2008. Direct estimates of pedogenic magnetite as a tool to reconstruct past climates from buried soils. Journal of Geophysical Research 113, B11102.

Geiss, C. E., Zanner, C. W., 2006. How abundant is pedogenic magnetite? Abundance and grain size estimates for loessic soils based on rock magnetic analyses. Journal of Geophysical Research 111, B12S21.

Gingerich, P. D., 2001. Biostratigraphy of the continental Paleocene-Eocene 
boundary interval on Polecat Bench in the northern Bighorn Basin. University of Michigan Papers on Paleontology 33, 37-67.

Heslop, D., Dekkers, M. J., Kruiver, P. P., van Oorschot, I. H. M., 2002. Analysis of isothermal remanent magnetization acquisition curves using the expectation-maximization algorithm. Geophysical Journal International $148,58-64$.

Heslop, D., Roberts, A. P., 2013. Calculating uncertainties on predictions of palaeoprecipitation from the magnetic properties of soils. Global and Planetary Change 110, 379-385.

Hyland, E., Sheldon, N. D., Van der Voo, R., Badgley, C., Abrajevitch, A., 2015. A new paleoprecipitation proxy based on soil magnetic properties: implications for expanding paleoclimate reconstructions. Geology $125,975-981$.

Hyland, E. G., Sheldon, N. D., 2016. Examining the spatial consistency of palaeosol proxies: implications for palaeoclimatic and palaeoenvironmental reconstructions in terrestrial sedimentary basins. Sedimentology 63, 959971.

Kraus, M. J., 2001. Sedimentology and depositional setting of the Willwood 
Formation in the Bighorn and Clarks Fork Basins. University of Michigan Papers on Paleontology 33, 15-28.

Kraus, M. J., Hasiotis, S. T., 2006. Significance of different modes of rhizolith preservation to interpreting paleoenvironmental and paleohydrologic settings: examples from Paleogene paleosols, Bighorn Basin, Wyoming, U.S.A. Journal of Sedimentary Research 76, 633-646.

Kraus, M. J., McInerney, F. A., Wing, S. L., Secord, R., Baczynski, A. A., Bloch, J. I., 2013. Paleohydrologic response to continental warming during the Paleocene-Eocene Thermal Maximum, Bighorn Basin, Wyoming. Palaeogeography, Palaeoclimatology, Palaeoecology 370, 196-208.

Kraus, M. J., Riggins, S., 2007. Transient drying during the PaleoceneEocene Thermal Maximum (PETM): analysis of paleosols in the bighorn basin, Wyoming. Palaeogeography, Palaeoclimatology, Palaeoecology 245, $444-461$.

Kraus, M. J., Woody, D. T., Smith, J. J., Dukic, V., 2015. Alluvial response to the Paleocene-Eocene Thermal Maximum climatic event, Polecat Bench, Wyoming (U.S.A.). Palaeogeography, Palaeoclimatology, Palaeoecology 435, 177-192.

Kruiver, P. P., Dekkers, M. J., Heslop, D., 2001. Quantification of magnetic 
coercivity components by the analysis of acquisition curves of isothermal remanent magnetisation. Earth and Planetary Science Letters 189, 269 276.

Lindquist, A. K., Feinberg, J. M., Waters, M. R., 2011. Rock magnetic properties of a soil developed on an alluvial deposit at Buttermilk Creek, Texas, USA. Geochemistry, Geophysics, Geosystems 12, Q12Z36.

Liu, Q., Banerjee, S., Jackson, M. J., 2002. A new method in mineral magnetism for the separation of weak antiferromagnetic signal from a strong ferrimagnetic background. Geophysical Research Letters 29, 1565.

Liu, Q., Roberts, A. P., Torrent, J., Horng, C. S., Larrasoaña, J. C., 2007. What do the HIRM and S-ratio really measure in environmental magnetism? Geochemistry, Geophysics, Geosystems 8, Q09011.

Long, X., Ji, J., Balsam, W., 2011. Rainfall-dependent transformations of iron oxides in a tropical saprolite transect of Hainan Island, South China: spectral and magnetic measurements. Journal of Geophysical Research 116, F03015.

Maher, B., Alekseev, A., Alekseeva, T., 2003. Magnetic mineralogy of soils across the Russian Steppe: climatic dependence of pedogenic magnetite 
formation. Palaeogeography, Palaeoclimatology, Palaeoecology 201, 321341.

Maher, B., Possolo, A., 2013. Statistical models for use of palaeosol magnetic properties as proxies of palaeorainfall. Global and Planetary Change 111, 280-287.

Maher, B. A., 1998. Magnetic properties of modern soils and Quaternary loessic paleosols: paleoclimatic implications. Palaeogeography, Palaeoclimatology, Palaeoecology 137, 25-54.

Maher, B. A., Karloukovski, V. V., Mutch, T. J., 2004. High-field remanence properties of synthetic and natural submicrometre haematites and goethites: significance for environmental contexts. Earth and Planetary Science Letters 226, 491-505.

Maher, B. A., Thompson, R., 1995. Paleorainfall reconstructions from pedogenic magnetic susceptibility variations in the Chinese Loess and Paleosols. Quaternary International 44, 383-391.

Maxbauer, D. P., Feinberg, J. M., Fox, D. L., 2016. Magnetic mineral assemblages in soils and paleosols as the basis for paleoprecipitation proxies: a review of magnetic methods and challenges. Earth-Science Reviews 155, $28-48$. 
McInerney, F. A., Wing, S. L., 2011. The Paleocene-Eocene Thermal Maximum: a perturbation of carbon cycle, climate, and biosphere with implications for the future. Annual Reviews of Earth and Planetary Sciences $39,489-516$.

Morón, S., Fox, D. L., Feinberg, J. M., Jaramillo, C., Bayona, G., Montes, C., Bloch, J. I., 2013. Climate change during the Early Paleogene in the Bogotá Basin (Colombia) inferred from paleosol carbon isotope stratigraphy, major oxides, and environmental magnetism. Palaeogeography, Palaeoclimatology, Palaeoecology 388, 115-127.

Orgeira, M. J., Egli, R., Compagnucci, R. H., 2011. A quantitative model of magnetic enhancement in loessic soils. In: Petrovský, E., Ivers, D., Harinarayana, T., Herrero-Bervera, E. (Eds.), The Earth's Magnetic Interior. Springer, Dordrecht, Netherlands, pp. 361-397.

Özdemir, Ö., Dunlop, D. J., 2014. Hysteresis and coercivity of hematite. Journal of Geophysical Research: Solid Earth, 2582-2594.

Rankey, E. C., Farr, M. R., 1997. Preserved pedogenic mineral magnetic signature, pedogenesis, and paleoclimate change: Pennsylvanian Roca Shale (Virgilian, Asselian), central Kansas, USA. Sedimentary Geology 114, 1132. 
Retallack, G. J., 1991. Untangling the effects of burial alteration and ancient soil formation. Annual Reviews of Earth and Plantary Sciences 19, 183206.

Retallack, G. J., Sheldon, N. D., Cogoini, M., Elmore, R., 2003. Magnetic susceptibility of early Paleozoic and Precambrian paleosols. Palaeogeography, Palaeoclimatology, Palaeoecology 198, 373-380.

Roberts, A. P., 2015. Magnetic mineral diagenesis. Earth-Science Reviews $151,1-47$.

Roberts, A. P., Cui, Y., Verosub, K. L., 1995. Wasp-waisted hysteresis loops: mineral magnetic characteristics and discrimination of components in mixed magnetic systems. Journal of Geophysical Research: Solid Earth 100, 17909-17924.

Rochette, P., Mathé, P. E., Esteban, L., Rakoto, H., Bouchez, J. L., Liu, Q., Torrent, J., 2005. Non-saturation of the defect moment of goethite and fine-grained hematite up to 57 Teslas. Geophysical Research Letters 32, L22309.

Smith, J. J., Hasiotis, S. T., Kraus, M. J., Woody, D. T., 2008. Relationship of floodplain ichnocoenoses to paleopedology, paleohydrology, and paleocli- 
712

713

714

715

716

717

718

719

720

721

722

723

724

725

726

mate in the Willwood Formation, Wyoming, during the Paleocene-Eocene Thermal Maximum. Palaios 23, 683-699.

Tauxe, L., Mullender, T. A. T., Pick, T., 1996. Potbellies, wasp-waists, and superparamagnetism in magnetic hysteresis. Journal of Geophysical Research: Solid Earth 101, 571-583.

Tramp, K. L., Soreghan, G. L., Elmore, R. D., 2004. Paleoclimatic inferences from paleopedology and magnetism of the Permian Maroon Formation loessite, Colorado, USA. Geological Society of America Bulletin 116, 671686.

van Velzen, A. J., Dekkers, M. J., 1999. Low-temperature oxidation of magnetite in loess-paleosol sequences: a correction of rock magnetic parameters. Studia Geophysica et Geodaetica 43, 357-375.

Wing, S. L., Harrington, G. J., Smith, F. A., Bloch, J. I., Boyer, D. M., Freeman, K. H., 2005. Transient floral change and rapid global warming at the Paleocene-Eocene boundary. Science 310, 993-996. 